\title{
The Relationship between Digit Ratio (2D:4D), Anaerobic Power and Athletic Ability of Young Athletes
}

\author{
Hüseyin Özden Yurdakul, Gökmen Özen*, Hürmüz Koç \\ Faculty of Sport Sciences, Çanakkale Onsekiz Mart University, Çanakkale, Turkey
}

Copyright $\mathrm{C} 2018$ by authors, all rights reserved. Authors agree that this article remains permanently open access under the terms of the Creative Commons Attribution License 4.0 International License

\begin{abstract}
The aim of this study is to examine whether there was a relationship between digit ratio (2D:4D) with anaerobic power and athletic performance of young athletes. Two hundred and fifty well-trained young male athletes were recruited as participants. Anthropometric measurements (body height, weight, and digit length) vertical jump and athletic ability tests were performed on each participant, for data analysis, correlation analysis was used. Data analyses indicated that the means of 2D:4D ratio was not correlated with BMI, anaerobic power and athletic ability scores $(p<.05)$. According to the findings of this study, the 2D:4D ratio does not seem to be an indicator parameter to predict the physical performance and athletic abilities of young athletes.
\end{abstract}

Keywords Ability, Anaerobic Power, Athlete, Digit Ratio

\section{Introduction}

The ratio of $4^{\text {th }}$ finger (ring finger $=4 D$ ) to $2^{\text {nd }}$ finger (index finger $=2 \mathrm{D}$ ) length of the hand is called the digit ratio (2D:4D) [16]. The digit ratio is determined by measured the lengths of 2D and 4D digits from the mid-point of bottom crease where the finger joins the hand to the tip of the finger. This ratio is generally accepted as a valid predictive marker of the exposure and sensitivity to prenatal androgen. Scientific researches revealed that there was a causative connection between prenatal androgen exposure and digit growth [13]. The findings of these researches indicated that the degree of prenatal testosterone exposure is negatively related to the 2D:4D ratios while the degree of prenatal estrogen exposure with positively. Therefore, the 2D:4D ratio serves as a biological marker to predict the level of testosterone on the body [14, 18, 19].

Testosterone as an androgenic sex hormone and one of the most important hormones assist with muscular growth, thrive, and muscle damage repairs on the human body [11, 13]. A number of researchers observed that the higher level of testosterone on the body can cause high athletic performance in various sports disciplines such as; rowing, sprinting, football, rugby. These researchers have also asserted that the physical performances of athletes can be estimated according to their digit ratios. Their results have revealed that a strong negative relationship between the digit ratio and the high athletic performance [9, 10, 17]. In this context, digit ratio may be considered as a predictive marker of athletic performance. However, some researchers have observed no meaningful relationship between digit ratio and athletic performance [7, 8, 12, 20]. Therefore, there is some disagreement with regard to whether the digit ratio is a discriminating parameter for the physical performance of athletes. Recently, scientific studies have been conducted to explain this contradiction. These studies have commonly focused on adult athletes groups in various sports disciplines. In this context, the aim of this study is to examine whether there was a relationship between digit ratio (2D:4D) with anaerobic power and athletic performance of young athletes.

\section{Materials and Methods}

\subsection{Participants}

Two hundred and fifty well-trained young male athletes who had at least 2 years of athletic training experience were recruited as participants. Their age was $19.4 \pm 4.25$ years, body height was $176.9 \pm 6.71 \mathrm{~cm}$, and weight was $68.39 \pm 8.39 \mathrm{~kg}$. The aim and the study protocol of this research were explained to all participants. The participants voluntarily consented to participate in the study. Written informed consent was obtained from each participant before the study performed. Participants' demographic data are demonstrated in Table 1.

Table 1. Demographic characteristics of the participants.

\begin{tabular}{cccccc}
\hline Variables & n & Min. & Max. & Mean & SD \\
\hline Age $($ year $)$ & 250 & 18 & 23 & 19.4 & 2.25 \\
\hline Height $(\mathrm{cm})$ & 250 & 156 & 195 & 176.9 & 6.7 \\
\hline Weight $(\mathrm{kg})$ & 250 & 47.4 & 94.25 & 68.39 & 8.39 \\
\hline BMI $\left(\mathrm{kg} / \mathrm{m}^{2}\right)$ & 250 & 16.69 & 28.14 & 21.86 & 2.25 \\
\hline
\end{tabular}




\subsection{Study Procedure}

This study was conducted in the city of Çanakkale in Turkey during the year 2018. All procedures were conducted in accordance with the Declaration of Helsinki. To determine anthropometric characteristics of participants was measured body height, weight and calculated Body Mass Index (BMI). To determine participants' anaerobic power and athletic ability was performed vertical jump (VJ) test and general ability test respectively. Prior to all tests and measurements, all participants were fully informed about the measurements and tests procedures. Each participant warmed up for 10 minutes before the athletic performance tests.

\subsection{Data Collection}

\section{Anthropometry and Body Composition}

All anthropometric measurements were taken using standardized techniques and calibrated equipment. The anthropometric measurement was taken after the participant's shoes, extra weights and clothes were taken off. Participants' body height (in $\mathrm{cm}$ ) was measured using a stadiometer (Seca 214, Germany) calibrated in millimeters and their body weight (in $\mathrm{kg}$ ) was obtained using a balance beam scale (Seca 700, Germany). According to obtained these data, each participant's BMI was computed using the following formula: body mass $(\mathrm{kg}) / \mathrm{height}^{2}(\mathrm{~m})$. In order to calculate digit ratios (2D:4D) of participants, the length of the index and ring fingers were measured directly on the ventral surface of the right hand from the crease proximal to the palm to the tip of the finger. Finger length measurements were taken by a specialist physiotherapist using a digital caliper with accuracy of $0.01 \mathrm{~mm}$ (Mitutoyo Absolute 700-113-10, Mitutoyo America Corp, Plymouth, Mich). Finger measurements were taken twice, and the digit ratio was computed. In order to eliminate bias due to inter-observer errors, all finger measurements were made by one physiotherapist. The 2D:4D ratio of participants was computed by dividing the length of the index finger (2D) by that of the ring finger (4D). Participants who reported injuries to their index or ring fingers were excluded from this study.

\section{Vertical Jump Test}

The vertical jump test is widely using a device to measure the anaerobic power. The vertical jump test was made by using a Takei digital jump meter (5414 jump-DF, Takei, Japan). The jump technique was demonstrated to all participants. The jump belt was connected to the elastic mat by a cord. The participants performed a countermovement jump as high as possible. The test was performed three times with 10-15 seconds rest between each trial. The vertical jump test scores were obtained from the digital display screen on the belt and their highest score recorded. The highest jump score was used for calculation of anaerobic power output. Anaerobic power was derived from the equation of Lewis: Average Power $\left(\mathrm{kg} / \mathrm{m} / \mathrm{sec}^{-1}\right)=$ $((\sqrt{ } 4,9 *$ Body Mass $(\mathrm{kg})) * \sqrt{ } \mathrm{Jump}$ distance $(\mathrm{m}))[15]$.

\section{Athletic Ability Test}

The athletic ability test which included a wide range of different athletic ability and skill task sub-tests was performed to evaluate the general athletic abilities of young athletes. The athletic performance data of participants were obtained using a specific athletic ability test which consists of sub-tests: front roll, double leg zigzag jump, basketball dribbling, miniature penalty-kick shootout, volleyball wall passing, handball $7 \mathrm{~m}$ free throw, hurdles over-under-over, jump the between asymmetric parallel bar. The athletic ability test was comprised of eight stations in which they performed athletic ability and skill tasks. Each sub-test has instructions on proper administration. The testing procedure is standardized for all participants. Their athletic ability test time was recorded using a photocell. The ability tests were performed in an indoor gym with tartan surface and under the same environmental conditions (at air temperature $20-22^{\circ} \mathrm{C}$ and with $50-55 \%$ relative air humidity). The ability tests were performed two times and best of two trials was taken as the score. The ability test flowing chart was presented in Figure 1. 

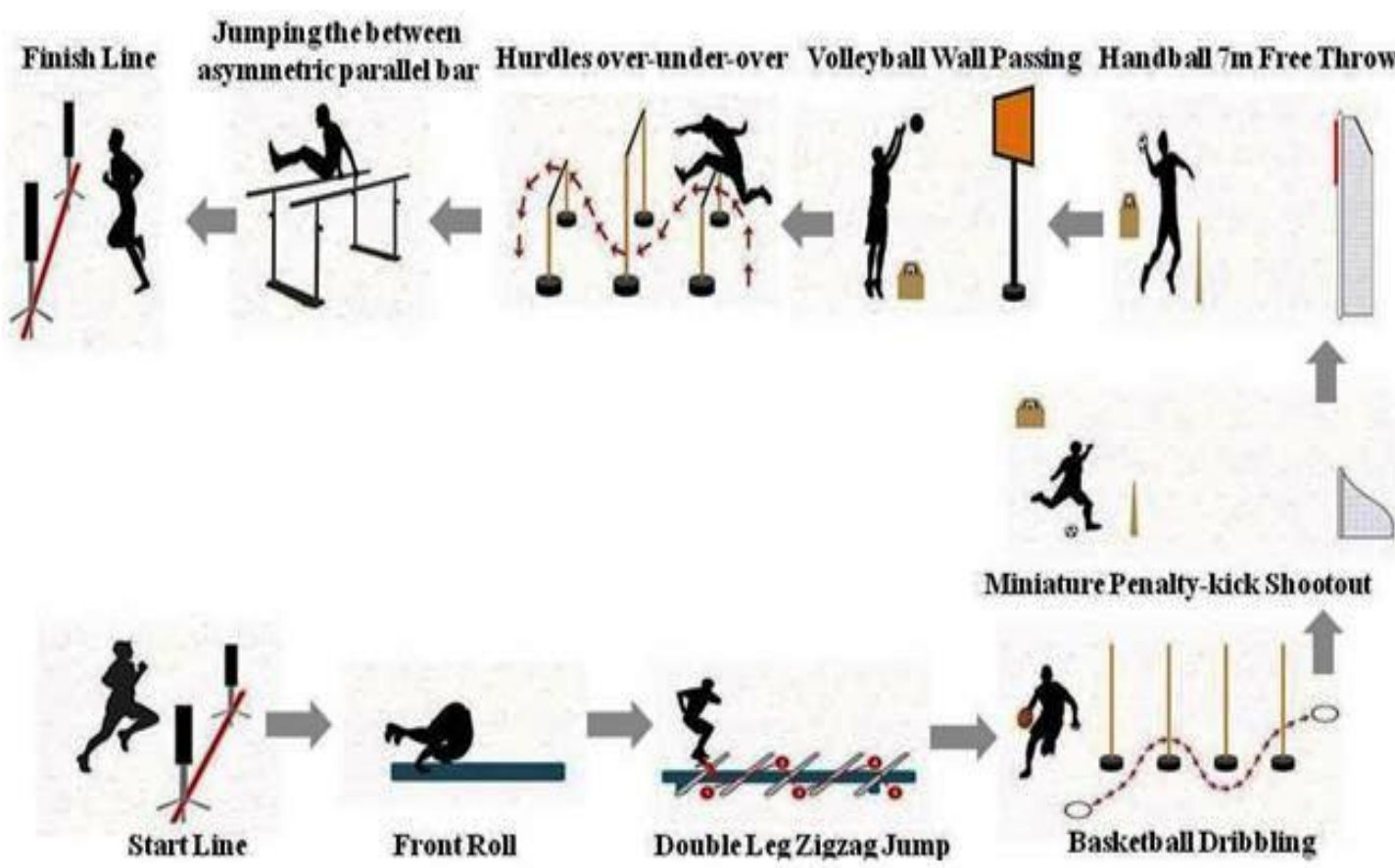

Figure 1. The flowing chart of the athletic ability test

\subsection{Statistical Analyses}

Statistical analyses were carried out using SPSS statistic software package (version 17, SPSS Inc., Chicago, IL, USA). The descriptive data are presented as means (M) and standard deviation $( \pm \mathrm{SD})$. Kolmogorov Smirnov normality test was applied to determine that data was acceptable with regard to homogeneity. As variances shows a normal distribution, the relationship between the 2D:4D ratio, the anaerobic power and athletic ability score were determined by the Pearson correlation coefficient. Inter-observer agreement for the first and second digit measurements, anaerobic power and athletic ability tests of participants were examined using Cohen's kappa coefficient statistic $(\kappa)$ with single-score intraclass correlation coefficients. The significance level was set at $5 \%$ for all inferential statistics.

\section{Results}

Cohen's $\kappa$ statistic was calculated to assess the repeatability of digit length measurements, vertical jump, and ability tests. The $\kappa$ statistic for the measurements of 2D:4D, vertical jump and ability test scores demonstrated the high intra-class correlation coefficients $\left(r_{1}=0.98,96\right.$, 95 respectively). The results of first measurements and test scores strongly correlated with the results recorded from second measurements/test scores $(\kappa>0.80)$

Table 2 present the mean, minimum, maximum values and standard deviations for the anthropometric and performance data. According to the data from Table 2, participants' the mean of the 2D length $(72.4 \pm 4.51 \mathrm{~mm})$ were higher than their 4D length $(72.9 \pm 4.62) \mathrm{mm}$. The mean of participants' digit ratio (2D:4D) was $0.99 \pm 0.03$ $\mathrm{mm}$ (ranged 0.89-1.10), their vertical jump score was $55.73 \pm 7.38 \mathrm{~cm}$, anaerobic power was $136.1 \pm 12.49$ $\mathrm{kg} / \mathrm{m} / \mathrm{sec}^{1}{ }^{1}$, ability test time was $34.15 \pm 6.12 \mathrm{sec}$.

Table 2. The digit length and athletic performance data of participants.

\begin{tabular}{ccccc}
\hline Variables & Min. & Max. & Mean & SD \\
\hline 2D $(\mathrm{mm})$ & 54 & 88 & 72.4 & 4.51 \\
\hline 4D $(\mathrm{mm})$ & 56 & 89 & 72.9 & 4.62 \\
\hline 2D:4D & 0.89 & 1.10 & 0.99 & 0.03 \\
\hline Vertical Jump $(\mathrm{cm})$ & 20 & 76 & 55.73 & 7.38 \\
\hline Anaerobic Power $\left(\mathrm{kg} / \mathrm{m} / \mathrm{sec}^{1}{ }^{1}\right)$ & 91 & 177 & 136.1 & 12.49 \\
\hline Ability Test Time $(\mathrm{sec})$ & 25.22 & 57.61 & 34.15 & 6.12 \\
\hline
\end{tabular}

Table 3 demonstrates the relationship between digit ratios (2D:4D) with anaerobic power and athletic ability score performance of participants. The means of 2D:4D ratio was not correlated with BMI, anaerobic power and athletic ability scores $(p<.05)$. On the other hand, BMI significantly correlated with anaerobic power of participants $(r=.477, \mathrm{p}<.001)$ while anaerobic power negatively correlated athletic ability test time $(r=-.246, p$ $<.001)$.

Table 3. The results of Pearson correlation coefficient analysis

\begin{tabular}{|c|c|c|c|c|c|}
\hline Variables & & 2D:4D & BMI & $\begin{array}{l}\text { Anaerobic } \\
\text { Power }\end{array}$ & $\begin{array}{c}\text { Ability } \\
\text { Score }\end{array}$ \\
\hline \multirow{2}{*}{$2 \mathrm{D}: 4 \mathrm{D}$} & $r$ & \multirow{2}{*}{1} & -.032 & -006 & -.014 \\
\hline & $p$ & & .31 & .46 & .41 \\
\hline \multirow{2}{*}{ BMI } & $r$ & - & \multirow{2}{*}{1} & $.477^{*}$ & -.052 \\
\hline & $p$ & - & & .000 & .21 \\
\hline \multirow{2}{*}{$\begin{array}{l}\text { Anaerobic } \\
\text { Power }\end{array}$} & $r$ & - & - & \multirow{2}{*}{1} & $-246^{*}$ \\
\hline & $p$ & - & - & & .000 \\
\hline \multirow{2}{*}{ Ability Score } & $r$ & - & - & - & \multirow{2}{*}{1} \\
\hline & $p$ & - & - & - & \\
\hline
\end{tabular}

Note: *; $<.05$ 


\section{Discussion}

In the present study, we addressed this issue by examining the relationships between the digit ratio (2D:4D), anaerobic power and athletic ability in well-trained young male athletes. Many researchers reported that digit ratio was negatively linked with prenatal testosterone while it was positively linked with estrogen exposure $[13,21]$. It is mostly considered that low 2D:4D ratios are associated with higher degree of prenatal testosterone exposure [5]. Numerous studies revealed that links between the level of testosterone and body composition and/or muscle mass in later life $[6,18]$. Moreover, some researchers dictated that prenatal testosterone have organizing effects on physical performance [4]. However, the relationship between prenatal testosterone and physical performance in later life is still argued by researchers $[3,12,20]$.

Previous findings in the literature on this topic have shown elite athletes have low 2D:4D ratios in the between 0.90 and $1.00 \mathrm{~mm}[1,3,9,13]$. Similarly, the mean of participants' digit ratio (2D:4D) was $0.99 \pm 0.03 \mathrm{~mm}$ (ranged 0.89- 1.10) and this finding concurred with reported digit ratio range in previous studies. On the other hand, young male athletes' digit ratio in this study no correlated their anaerobic power and athletic ability scores $(p>.05)$. It is generally considered that the level of testosterone on body influence the improve speed, endurance, muscular strength, and body composition [11]. However, our findings show that prenatal testosterone has no permanent effect on physical performance in later life. In this regard, some researchers' claims seem to be somewhat exaggerated. By calculating, the 2D:4D ratio does not seem to be an indicator parameter to predict the physical performance and skills of athletes. According to our results, this suggestion has been supported by some previous studies showing no significant relationship between 2D:4D ratio and physical performance among different groups $[2,8,12,20]$.

\section{Conclusions}

As a result, the findings of this study indicated that the 2D:4D digit ratio no correlated with anaerobic power and athletic ability of young male athletes. Therefore, 2D:4D ratio is not a predictive marker of athletic performance for young athletes.

\section{Acknowledgements}

We gratefully acknowledge the help of all the participants who took part in the study.

\section{REFERENCES}

[1] Bescós, R., Esteve, M., Porta, J., Mateu, M., Irurtia, A., Voracek, M. (2009). Prenatal programming of sporting success: Associations of digit ratio (2D:4D), a putative marker for prenatal androgen action, with world rankings in female fencers, J Sports Sci, 27(6), 625-632.

[2] Çelik, A., Aksu, F., Tunar, M., Daşdan, A.E.N., Topaçoğlu, H. (2010). Effects of digit ratio of master athletes on sporting achievement levels. DEÜ Tip Fakültesi Dergisi, 24(3), 89-93.

[3] Eler, N., Eler, S. (2018). 2D: 4D, Lateralization and Strength in Handball Players. Journal of Education and Training Studies, 6(5), 170-178.

[4] Fink, B., Thanzami, V., Seydel, H., Manning, J.T. (2006). Digit ratio and hand-grip strength in German and Mizos men: Cross-cultural evidence for an organizing effect of prenatal testosterone on strength. American Journal of Human Biology: The Official Journal of the Human Biology Association, 18(6), 776-782.

[5] García-Cruz, E., Huguet, J., Piqueras, M., Ribal, M.J., Alcaraz, A. (2012). Second to fourth digit ratio, adult testosterone level and testosterone deficiency. BJU Int, 109(2), 266-271.

[6] Holzapfel, S.D., Chomentowski III, P.J., Summers, L.A.M., Sabin, M.J. (2016). The relationship between digit ratio (2D:4D), $\mathrm{VO}_{2 \max }$, ventilatory threshold, and running performance. International Journal of Sports Sciences \& Fitness, 6(1), 1-30.

[7] Hönekopp, J., Schuster, M. (2010). A meta-analysis on 2D: 4D and athletic prowess: Substantial relationships but neither hand out-predicts the other. Personality and Individual Differences, 48(1), 4-10.

[8] Jia, J. (2014).Research on the relationship of the digit ratio and the throwing ability of throwing athlete in sports undergraduate college. Bio Thecnology An Indian Journal. 10(9): 3698-3703.

[9] Kilduff, L., Cook, C.J., Bennett, M., Crewther, B., Bracken, R.M., Manning, J. (2013). Right-left digit ratio (2D: 4D) predicts free testosterone levels associated with a physical challenge. J Sports Sci, 31(6), 677-683.

[10] Kim, T.B., Kim, K.H. (2016). Why is digit ratio correlated to sports performance?. J Exerc Rehabil, 12(6), 515-519

[11] Liu, T.C., Kuo, C.H., Wang, P.S. (2009). Exercise and testosterone. Adaptive Medicine, 1(1), 26-31.

[12] Lombardo, M.P., Otieno, S., Heiss, A. (2018). College-aged women in the United States that play overhand throwing sports have masculine digit ratios. PloS One, 13(9), $\mathrm{e} 0203685$.

[13] Longman, D., Stock, J.T., Wells, J.C. (2011). Digit ratio (2D:4D) and rowing ergometer performance in males and females. , 144(3), 337-41.

[14] Lutchmaya, S., Baron-Cohen, S., Raggatt, P., Knickmeyer, R., Manning, J.T. (2004). 2nd to 4th digit ratios, fetal testosterone and estradiol. Early Hum Dev, 77, 23-28.

[15] Manning J.M., Dooly-Manning C., Perrin D.H. (1998), 
Factor analysis of various anaerobic power tests. $J$ Sports Med Phys Fitness. 28(2):138-44.

[16] Manning, J.T, Scutt, D., Wilson, J., Lewis-Jones, D.I. (1998). The ratio of 2 nd to 4 th digit length: a predictor of sperm numbers and concentration of testosterone, luteinizing hormone, and oestrogen. Hum Reprod 13(11): 3000-3004.

[17] Manning, J.T., Taylor, R.P. (2001). Second to fourth digit ratio and male ability in sport: implications for sexual selection in humans. Evolution and Human Behavior, 22(1), 61-69.

[18] Manning, J.T. (2008). The Finger Ratio. London: Faber \& Faber.

[19] McIntyre, M.H. (2006). The use of digit ratios as markers for perinatal androgen action. Reprod Biol Endocrinol, 4, 10.

[20] Peeters, M.W., Claessens, A.L. (2013). Digit ratio (2D: 4D) and competition level in world-class female gymnasts. $J$ Sports Sci, 31(12), 1302-1311.

[21] Voracek, M. (2011). Special issue preamble: Digit ratio (2D: 4D) and individual differences research. Personality and Individual Differences, 51(4), 367-370. 